\title{
OCCUPATIONAL HEALTH OF MIDWIVES
}

\author{
Richard Pougnet ${ }^{1,2,3}$, Laurence Pougnet ${ }^{4}$, Moriamo Eniafe-Eveillard ${ }^{1}$, Brice Loddé1,5 \\ ${ }^{1}$ Morvan University Hospital, Brest, France \\ Occupational Diseases Center \\ ${ }^{2}$ Université de Bretagne Occidentale, Brest, France \\ Laboratoire d'Etudes et de Recherches en Sociologie (LABERS), EA 3149 \\ ${ }^{3}$ Université de Bretagne Occidentale, Brest, France \\ Service Universitaire de Prévention et de Promotion de la Santé (SUMPPS) \\ ${ }^{4}$ Clermont-Tonnerre Military Hospital, Brest, France \\ ${ }^{5}$ Université de Bretagne Occidentale, Brest, France \\ Optimisation des Régulations Physiologiques (ORPHY), EA 4324
}

\begin{abstract}
The midwifery profession varies greatly from one country to another. There are, however, a number of common features such as exposure to biological risks through contact with pregnant women and women in labor, exposure to postural stresses during examinations and medical acts, but also, increasingly, exposure to organizational constraints (work schedules, shift work, etc.). This article aims to give an overview of what is known about the occupational health risks of midwives (MWs). A review of the literature on Medline, from January 1, 2006 to December 31, 2017, was carried out. Articles focused principally on burnout (BO) and post-traumatic stress disorder. Several BO questionnaires were used. For the Copenhagen Burnout Inventory, the prevalence of personal BO ranged 20-57\%; the percentage of work-related BO fell between 15-57\%; and the prevalence of client-related BO ranged 5-15\%. For the Maslach Burnout Inventory, the prevalence of emotional exhaustion varied between 23-60.7\%; the prevalence of depersonalization ranged 3.3-30.3\%; and the pervasiveness of personal accomplishment varied between 5-30.3\%. There was little data concerning musculoskeletal problems or accidental exposure to biological fluids. The literature review on occupational pathologies demonstrates high levels of BO. Several gaps exist on the evolution of the impact of their work on the health of MWs, like the effect of shift work, postural stresses, etc. This review will make it possible to better focus future research on the occupational health of this population. Med Pr. 2020;71(4):473-81
\end{abstract}

Key words: midwifery, occupational health, occupational diseases, burnout syndrome, post-traumatic stress disorder, musculoskeletal diseases

Corresponding author: Richard Pougnet, Morvan University Hospital, Occupational Diseases Center, (CHRU Morvan, Centre de Pathologies Professionnelles) Av. Foch 2, 29200 Brest, France, e-mail: richard.pougnet@live.fr Received: May 21, 2019, accepted: January 31, 2020

\section{INTRODUCTION}

The midwifery profession is emotionally challenging. Contact with parents, torn between their hope and fear of bad news, is always a rich human experience. It engages midwives (MWs) at a psychological level [1]. It is also a profession of a thousand faces; not the faces of the children being born, but rather those of the MWs who practice in sometimes extreme conditions (mountains, etc.) or in a hospital setting [2]. The profession is evolving quickly, because the level of studies required varies from one country to another: some MWs undergo traditional training, while others follow university courses and complement them with scientific theses [3]. In France, for example, MWs have gradually acquired the status of a medical professional, on the same level as physicians, surgeons and dentists [4]. Wherever an MW practices, and whatever the level of studies that she/he has attained, MWs see their work as being rich in meaning and humanity [5].

Unfortunately, not all situations turn out favorably. Some births end in the death of the child or the mother. Some pregnancies are difficult and frightening for the parents who are filled with uncertainty about the future of their child. Obviously, MWs are not insensitive to this particular aspect of their profession. Some studies have shown that a high level of compassion is a factor in work-related fatigue [6]. Even during their training, students can suffer from emotional trauma and display signs of post-traumatic stress [7]. Such pa- 
thologies can also develop over the course of an MW's career [8]. Aside from these tragic events, work organization itself can have detrimental effects on health. Actually, the work schedule, the number of working hours, problems with the institutional hierarchy, a lack of human and material resources, etc., are all factors that can lead to professional burnout (BO) [9]. The inability to deal with all of these situations can also create a sense of shame [10]. Furthermore, because of their posture or the position necessary to carry out maneuvers required in the childbirth process, MWs are subject to physical constraints that can bring about musculoskeletal disorders (MSDs) [11].

In the face of all these constraints and health risks, prevention measures should be put in place. Some authors suggest ways of coping, for example [12]. However, to improve prevention, it seems useful to have an overview of the occupational health problems of MWs. This article proposes a review of the literature on the occupational pathologies of MWs over the last 10 years.

\section{METHODS}

A literature review was done using the medical database Medline, between January 1, 2006 and December 31,
2018. Searches were carried out in Medline, Scopus, Pascal and BDSP (Banque de Données en Santé Publique) in English, French and Spanish. The key words used were: "Nurse Midwives"[Mesh]; "Midwifery"[Mesh]; "Occupational Health"[Mesh]; "Occupational Diseases" [Mesh]. On Scopus, the same English words were used. In French and Spanish, the following expressions were used: "sage-femme," "sages-femmes," "santé au travail," "maladie professionnelle," "maladies professionnelles," "pateras," "salud ocupacional" and "enfermedad ocupacional" (Figure 1).

Burnout was defined as a reaction to the workplace. It is characterized by emotional exhaustion, cynicism and reduced professional fulfillment [13]. In fact, BO is not included in the Diagnostic and Statistical Manual of Mental Disorders (DSM-5). Post-traumatic stress disorder (PTSD) is a mental disorder which can be developed by someone after a traumatic event, such as a violent act. But it can also be developed after chronic stress [14]. This condition is described in DSM-5.

Only articles dealing with midwifery-related occupational health were included. Articles on health considerations for parents or children were, therefore, excluded, as were those for which it was not possible to determine whether the subjects were MWs or rather

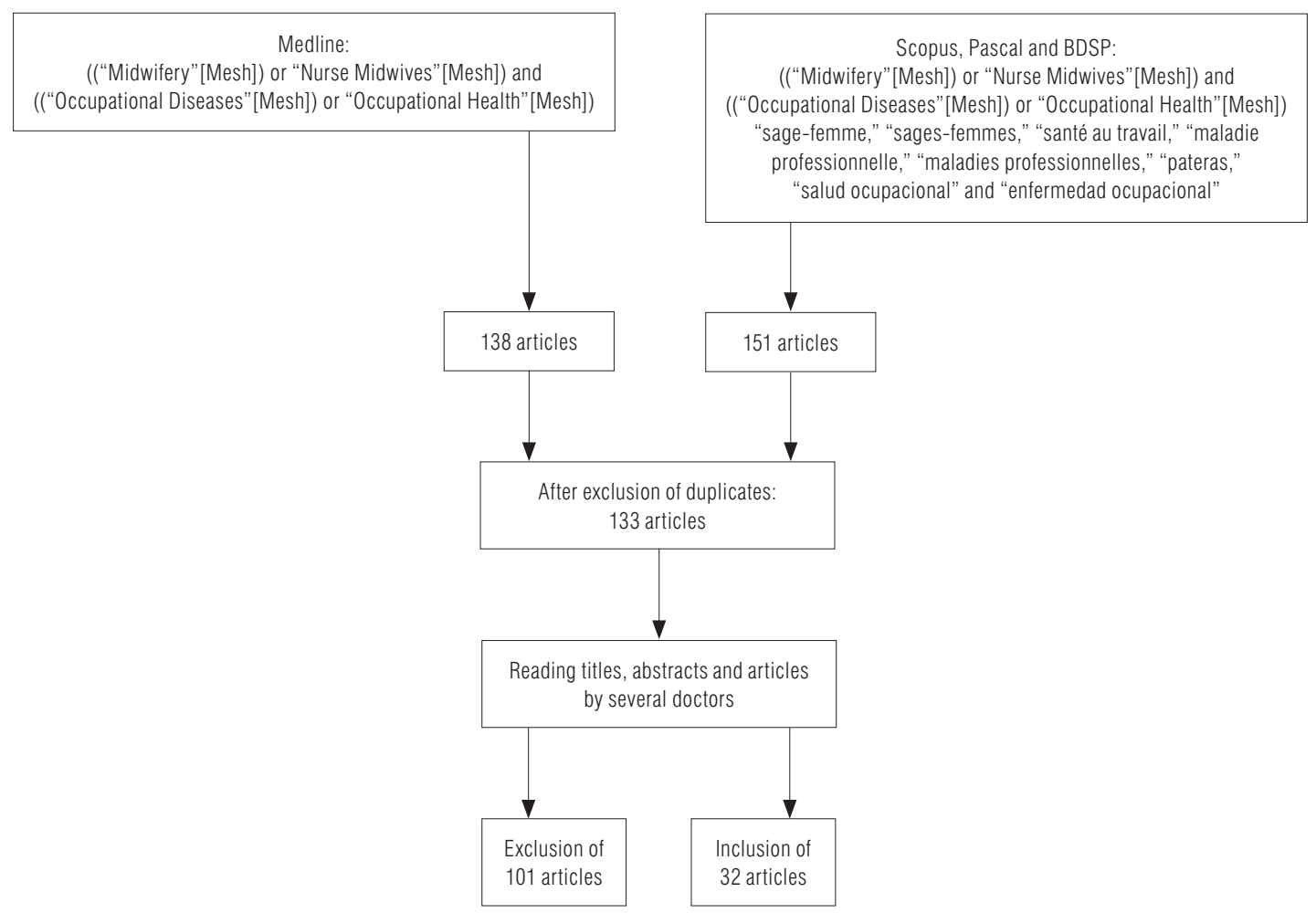

Figure 1. Articles selected for a review of literature between 2006 and 2018 concerning burnout among midwives 
neonatal nurses or physicians. At first, articles were selected by reading their titles and abstracts. Then, the selection was made using the text itself.

The conditions and health problems described in the articles were classified according to the type of the pathology. When several articles used the same methodology, it was possible to create virtual populations by taking the data from the articles, in order to attain the overall prevalence rates. For example, for $\mathrm{BO}$, several articles used the same questionnaire, with the same interpretation. The virtual population was thus the sum of the populations in all these articles and the overall prevalence was the sum of positive subjects in each article within this virtual population.

\section{RESULTS}

The main occupational health problems studied were the following: $\mathrm{BO}$, psychosocial risks (PSRs) and stress, or PTSD. Other health risks were studied, e.g., MSDs and blood exposure accidents (BEAs). One article dealt with allergy risks. It was a literature review on skin sensitization to latex protein [15]. No new cases had been described since 2005.

\section{Burnout and post-traumatic stress disorder}

The prevalence of $\mathrm{BO}$ was studied in 13 articles, among which 2 types of studies emerged: one type assessed BO using the Copenhagen Burnout Inventory (CPI), while the other type used the Maslach Burnout Inventory (MBI) (Table 1). The CPI studied 3 other forms of BO: personal $\mathrm{BO}$, work-related $\mathrm{BO}$ and client-related $\mathrm{BO}$. The levels of prevalence were the following: $20-57 \%$ for personal BO; $15-57 \%$ for work-related BO; and 5-15\% for client-related $\mathrm{BO}$.

The MBI studied 3 dimensions of BO: emotional exhaustion, depersonalization and personal accomplishment (Table 1). The levels of prevalence ranged: $23-$ $60.7 \%$ for emotional exhaustion; $3.8-30.3 \%$ for depersonalization; and 5-30.3\% for personal accomplishment.

A cross-sectional study in Uganda assessed the link between exhaustion, the quality of life and job satisfaction, using the following questionnaires: the Professional Quality of Life Scale, the Perceived Well-Being Scale and the Job Satisfaction Subscale [28]. The methodology used was, therefore, not comparable to the items in Table 1. Overall, 238 MWs participated. The mean scores on the Professional Quality of Life Scale showed an average compassionate satisfaction $(19 \pm 4.88), \mathrm{BO}(36.9 \pm 6.22)$ and secondary traumatic stress $(22.9 \pm 6.69)$. The midwives' compassion satisfaction was related to psychological well-being $(\mathrm{p}<0.01)$ and job satisfaction $(\mathrm{p}<0.01)$. Conversely, their BOlevels and secondary traumatic stress were associated with the educational level $(\mathrm{p}<0.01)$, marital status ( $p<0.01)$, involvement in non-midwifery health care activities $(\mathrm{p}<0.01)$, and physical well-being $(p<0.01)$. Compassion is correlated with both the quality of life and job satisfaction.

Some authors studied the link between the symptoms of BO and ethical issues. Mizuno et al. studied BO and job satisfaction in 86 MWs working in abortion clinics [29]. They used several standardized scales: the Professional Quality of Life Scale, and the Japanese version of the Frankfurt Emotional Work Scale. The results showed satisfaction at $34.6 \%$, fatigue $-22.1 \%$, and $\mathrm{BO}-$ $27 \%$. The stress factors "thinking that the aborted fetus deserved to live" and "difficulty in controlling emotions during abortion care" were associated with compassion fatigue.

Rees et al. have started surveillance of BO in Australia, among nurses. In 2018, they studied the link between BO and workplace violence [30]. They showed that $53 \%$ of the 2397 people who responded to the questionnaires regarding occupational violence had been victims of $\geq 1$ violent event in the previous 3 months. People who had been victims of violence were more likely to have $\mathrm{BO}$ than the others $(\mathrm{p}<0.05)$.

There were 3 original articles devoted to PTSD $[8,23,31]$. Prevalence fell between $32-36 \%$. In addition, 2 studies showed a link between PTSD and a serious incident at work, particularly death in neonatology [31].

\section{Psychosocial risks}

Several articles focused on PSRs according to other approaches. Several authors showed the socio-economic evolution of hospital work as being unfavorable for MWs' occupational health. In particular, the number of MWs tended to decrease despite the increasing need for care in several countries $[31,32]$. The analysis of organizational constraints showed several PSRs: staggered hours, value conflicts, such as working in an abortion room, or feeling that you do not have enough time to provide good care $[29,33,34]$. Another risk factor appears in the literature: external and internal violence at the hospital. For the first, it is verbal or physical aggression. Rodwell et al. showed that $21 \%$ of MWs were often verbally abused by patients or their loved ones [35]. Several prevention proposals have been given. Farrell 


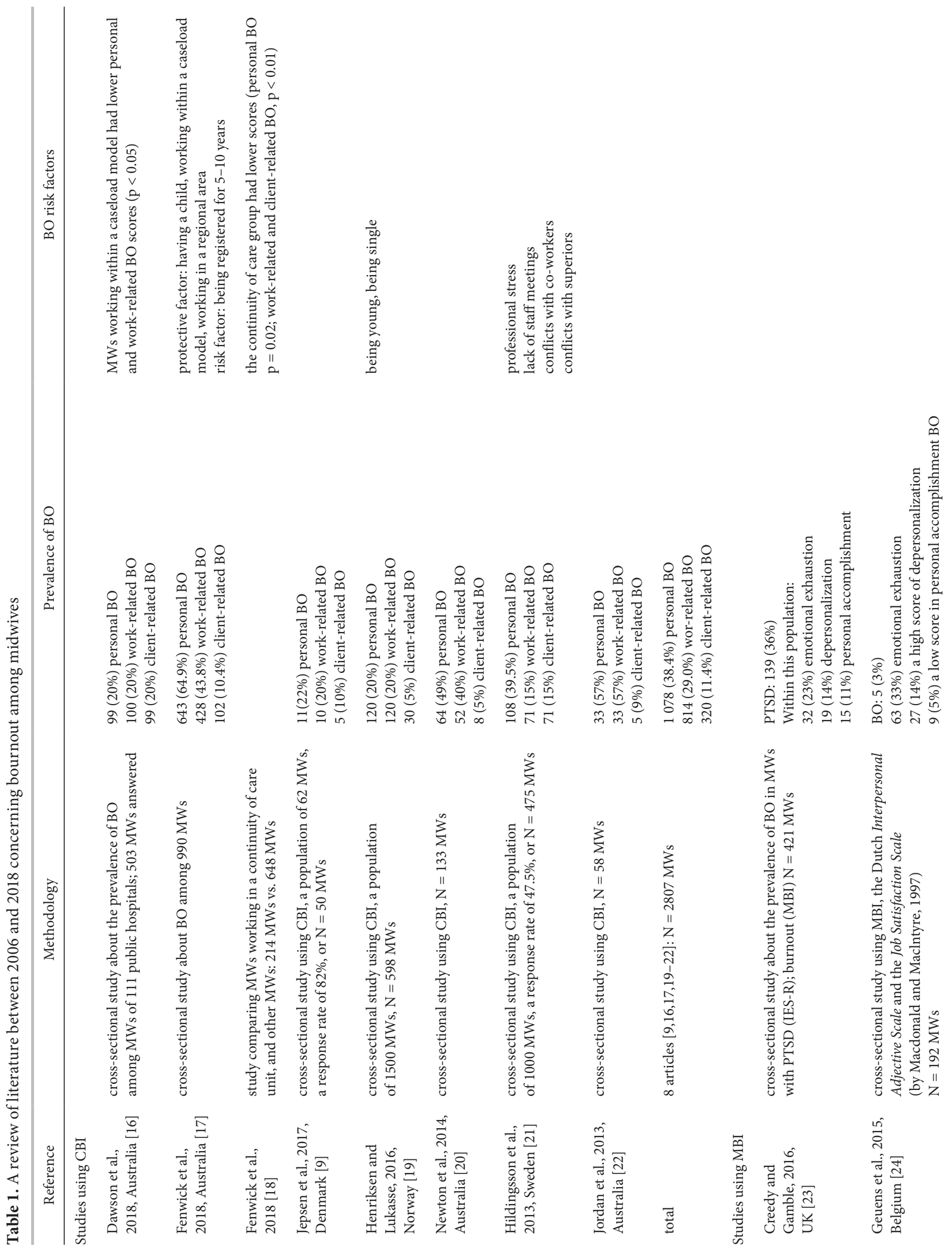


et al. made the following statement, "The study found more "protection" from assault when there was a high standard of patient facilities, sufficient staffing, effective enforcement of policies, and when staff were provided with personal protective equipment" [36]. The second type of violence involves violence within the care team. Rodwell et al. showed that $18.8 \%$ of MWs were victims of bullying and $1.5 \%$ of sexual harassment [35]. Relational problems at work can also be expressed as a cultural gap between different professions. So, the Birth Project Group has collected various testimonials from MWs. For them, fear is the main obstacle to well-being at work. This fear could be due to the organization of work or the climate of fear encouraged by gynecologists [37].

All these factors explain the prevalence of $\mathrm{BO}$, or the feeling of stress. Knezevic et al. studied stress among MWs with the Occupational Stress Assessment Questionnaire (OSAQ) for health-care workers and the Work Ability Index (WAI) questionnaire. They showed that $76.7 \%$ of MWs were stressed [38]. This is consistent with the study by Adgie et al. who found, through a self-questionnaire, that $48 \%$ of MWs were under stress daily and that $78 \%$ were stressed because of their workload [39].

Nonetheless, there were some protective factors. For example, Hildingsson et al. showed the following protective factors: the quality of private life, relations with the physician, or playing a leadership role at the hospital [32].

\section{Other occupational health problems}

Several studies have analyzed other occupational health issues, e.g., BEAs and musculoskeletal disorders MSDs.

The prevalence of BEAs is difficult to investigate, particularly because of a lack of systematic BEA reporting. One article showed that $40-80 \%$ of BEAs among Australian MWs were not declared due to a lack of time, knowledge of the risks or work organization [40]. Yet, MWs are considered a population at risk. Thus Askarian et al. studied the risk of BEAs over the entire career of MWs relative to nurses, comparing $146 \mathrm{MWs}$ and 145 nurses in Iran. The prevalence of having $\geq 1$ BEA over an entire career was $71 \%$ in MWs vs. $29 \%$ in nurses. The risk was thus significantly higher for MWs (OR: 4.72 [2.69-8.26]) [41].

The MW population is also at risk for MSDs [11]. Thiede et al. compared the most at-risk occupations for MSDs for women, relative to men, in a population of 2877 people (51.9\% women vs. $48.1 \%$ men) [ 42 ]. The 2 most at-risk professions were nursing and midwife- 
ry. The main factor, according to the authors, was the extreme postures that MWs must hold during care, especially deliveries. Other factors can lead to joint pain, such as lower leg pain associated with walking. Night work was not related to a higher prevalence of MSDs, according to the study by Burdelak et al. [43]. They studied pathologies in nurses and MWs who worked at night, in comparison with those who worked during the day. There was no significant difference. The authors thought it was a healthy worker effect, because night workers were significantly younger.

\section{DISCUSSION}

This review of the literature on occupational health problems in MWs over a period of 10 years has highlighted several issues that have been addressed: $\mathrm{BO}$, PTSD and PSRs, but also BEAs and MSDs. The main pathology studied was BO. The levels of prevalence were extremely variable from one country to another, or rather from one study to another. This review of the literature was an opportunity to determine the levels of prevalence in a virtual population when several articles studied BO with similar methodologies. Thus, using CPI in a virtual population of $1314 \mathrm{MWs}$, the authors found: 336 (25.6\%) personal BO; 286 (21.8\%) workrelated $\mathrm{BO}$; and 119 (9.1\%) client-related $\mathrm{BO}$, while using MBI in a virtual population of 669 MWs, they found: $253(37.8 \%)$ emotional exhaustion; 60 (8.9\%) a high score of depersonalization; and $69(10.3 \%)$ a low score in personal accomplishment $\mathrm{BO}$.

There are, however, several limitations to this literature review. The virtual population approach could be criticized. There could be duplicates of subjects from one study to another, or differences in the interpretation of the questionnaires. Given the diversity of countries, the risk of duplication seems low and negligible. Moreover, to avoid interpretation bias, only articles with the same objectives, the same standardized questionnaires and the same validated methods of interpretation were retained. For example, the article investigating the prevalence of BO in the subpopulation of MWs with PTSD was excluded from the analyses.

There may be some bias in the medical literature regarding MWs' emotional suffering at work. The articles mainly studied $\mathrm{BO}$, perhaps due to the fact that $\mathrm{BO}$, in general, has been greatly discussed recently. However, there are many reaction disorders at work. In particular, stress can become a reaction anxiety disorder, as can be seen in the health sector. The prevalence of anxiety dis- orders is $28 \%$ among physicians and $40 \%$ among nurses [44-46]. In addition, being around patients who are suffering, together with other work pressures, can also lead to mood disorders. These disorders are common among other caregivers. The prevalence of mood disorders among physicians ranged $13 \%-30 \%$ depending on the study $[45,47]$, while as regards nurses, some articles showed that $13.3 \%-18 \%$ suffered from serious depression $[48,49]$.

Studies focusing on these reactive psychiatric problems would make it possible to estimate the prevalence of these disorders. They would also allow one to link the reaction disorders (BO, anxiety, mood disorder) with the working conditions or with the type of pathologies encountered, or to disaffirm this link. For example, in a study of nurses with staggered hours, especially at night, Waage et al. showed that they had more depression, more sleep disturbances and a higher consumption of hypnotics than nurses without staggered schedules [50]. Night work is also identified as a breast cancer risk. In fact, MWs often have staggered hours, because many deliveries are at night. It would, therefore, be useful to better study the effects of this exposure. In addition, the health consequences to MWs from exposure to violence should be better studied. In this review, Rodwell et al. showed that nearly $20 \%$ of MWs experienced violence or harassment. Exposure to violence, whether verbal or physical, is known to cause mood disorders in caregivers [51]. The same is true for sexual harassment [52]. Therefore, the data in the literature about the impact of violence in the health care setting should be completed.

For BO, the literature review showed the main risk factors. This review of the literature included hourly volumes, staggered hours, and relations with colleagues or the institutional hierarchy. However, it would be useful to better specify the link with the working conditions themselves. There were no articles examining organizational models for types of work where employees are at a greater risk of suffering at work, such as the Karasek and Siegrist models, already used for health care workers [46]. Karasek's Job Content Questionnaire examines the work situation, based on 3 dimensions: decision latitude, psychological demand, and support from colleagues and the hierarchy. Job strain is defined by the combination of low decision latitude and high psychological demand, which can then be compounded in the case of low support. Such a work situation is known to cause reaction disorders. Studies using this questionnaire could improve primary prevention. 
For its part, Siegrist's questionnaire explores the balance of effort and rewards at work [53,54]. Each job requires consenting to efforts (workload, hourly volume, staggered hours, etc.). However, work brings rewards of different kinds (financial, social recognition, etc.). The psychic risk situation corresponds to an imbalance: too much effort for insufficient rewards. For MWs, the literature shows clear efforts identified in this review as risk factors for BO. However, it would be useful to identify the rewards perceived by MWs. For example, placing value on the profession, which is linked to life and birth, can be a strong element of stimulation, perhaps enough to mask certain efforts. The article on MWs in abortion rooms shows that ethical investment is a reward element. Perhaps it would be interesting to better identify the positive elements at work to increase them and, consequently, to reduce malaise at work.

This review of the literature could, therefore, assist in the prevention of $\mathrm{BO}$, because several protective and risk factors were identified. There have been several prevention programs. Some are focused on stress management, such as mindfulness racing. While these programs have shown some effectiveness, prevention should focus on the proven risk factors, as the reduction of these factors should make it possible to reduce BO.

Other risks have been little studied in the last decade. The midwifery profession can expose MWs to the risk of BEAs to varying degrees, depending on the exact roles of MWs. In France, as MWs are medical staff, they are required to suture parturients. They may, therefore, have a risk of BEAs, but also risk exposure to the placenta or amniotic fluid, in cases of projection onto the mucous membranes. This biological risk can lead to contamination: mainly HIV infections, hepatitis $B$ and hepatitis $C$ virus. During a BEA, caregivers may also suffer from acute stress or even develop PTSD. Finally, additional studies should focus on the risk of MSDs in this population. This is a health problem for caregivers in general. Midwives have to lean forward while they work, or even squat during deliveries. These positions may increase the risk of lumbar pathologies, such as sciatica, and knee pathologies, including hygroma. In addition, during pregnancy follow-up, the regular practice of ultrasounds, which involves abduction of the shoulder more than $60^{\circ}$ in the static position, exposes tendinopathies of the shoulder and sub-acromioclavicular conflicts. Field assessments should better quantify these pathologies and the postural constraints of MWs.

\section{CONCLUSIONS}

This literature review has shown the psychological risk of practising midwifery. In particular, numerous studies have evaluated the prevalence of $\mathrm{BO}$, along with the risk factors of this syndrome. There are factors intrinsic to individuals, but especially factors related to work organizations, such as staggered hours or a lack of service staff. This review also highlighted some shortcomings in the international literature on MWs' occupational health, as well as provided a synthetic view of the risk factors for $\mathrm{BO}$ that have been demonstrated. Prevention should target these factors as a priority. Otherwise, there is little data on the expected occupational risks such as BEAs and MSDs. This article will help professionals have some perspective on their practices and the risks to their health.

\section{REFERENCES}

1. Rayment J. Emotional labour: how midwives manage emotion at work. Pract Midwife. 2015;18(3):9-11.

2. Snyder A, Thatcher E. From the trunk of a Volkswagen beetle: a mobile nursing clinic in Appalachia. Fam Community Health. 2014;37(3):239-47, https://doi.org/10.1097/.

3. Turner C, Bain C, Schluter PJ, Yorkston E, Bogossian F, McClure R, et al. Nurses and Midwives e-cohort Group. Cohort Profile: The Nurses and Midwives e-Cohort Study - a novel electronic longitudinal study. Int J Epidemiol. 2009;38(1): 53-60, https://doi.org/10.1093/ije/dym294

4. Pinquier D, Gagneur A, Guen CG, Blandin S, Stephan JL, Régnier $\mathrm{F}$, et al. Vaccination en périnatalité: parents, enfants, professionnels. Gynecol Obstet Fertil. 2008;36(4): 461-8, https://doi.org/10.1016/j.gyobfe.2008.02.015.

5. Gibb S, Hundley V. What psychosocial well-being in the postnatal period means to midwives. Midwifery. 2007;23 (4):413-24.

6. Leinweber J, Rowe HJ. The costs of 'being with the woman': secondary traumatic stress in midwifery. Midwifery. 2010; 26(1):76-87, https://doi.org/10.1016/j.midw.2008.04.003.

7. Davies S, Coldridge L. 'No Man's Land': An exploration of the traumatic experiences of student midwives in practice. Midwifery. 2015;31(9):858-64, https://doi.org/10.1016/j.midw. 2015.05.001.

8. Sheen K, Spiby H, Slade P. Exposure to traumatic perinatal experiences and posttraumatic stress symptoms in midwives: prevalence and association with burnout. Int J Nurs Stud. 2015; 52(2):578-87, https://doi.org/10.1016/j.ijnurstu.2014.11.006.

9. Jepsen I, Juul S, Foureur M, Sørensen EE, Nøhr EA. Is caseload midwifery a healthy work-form? - A survey of burn 
out among midwives in Denmark. Sex Reprod Health. 2017;11:102-6, https://doi.org/10.1016/j.srhc.2016.12.001.

10. Steen M, Jones A. The burden of shame and stigma. Midwives. 2014;17(2):50-1.

11. Long MH, Bogossian FE, Johnston V. The prevalence of work-related neck, shoulder, and upper back musculoskeletal disorders among midwives, nurses, and physicians: a systematic review. Workplace Health Saf. 2013;61(5): 223-9, https//doi.org/10.3928/21650799-20130426-38.

12. Byrom S. Feeling the pressure: what can we do? Pract Midwife. $2014 ; 17(2): 46$.

13. Freudenberger, H. Lépuisement professionnel: La Brûlure interne. Québec: Gaétan Morin Éditeur; 1987.

14. Laurel Franklin C, Raines AM, Hurlocker MC. No traum, no problem: syndrome of posttraumatic stress in a absence of a criterion A Stressor. J Psychopathol Behav Assess. 2019;41(1):107-11.

15. Fletcher J. Latex allergy in women's health care. Pract Midwife. 2013;16(7):33-6.

16. Dawson K, Newton M, Forster D, McLachlan H. Comparing caseload and non-caseload midwives' burnout levels and professional attitudes: A national, cross-sectional survey of Australian midwives working in the public maternity system. Midwifery. 2018;63:60-7, https://doi.org/10.1016/ j.midw.2018.04.026.

17. Fenwick J, Lubomski A, Creedy DK, Sidebotham M. Personal, professional and workplace factors that contribute to burnout in Australian midwives. J Adv Nurs. 2018; 74(4):852-63, https://doi.org/10.1111/jan.13491.

18. Fenwick J, Sidebotham M, Gamble J, Creedy DK. The emotional and professional wellbeing of Australian midwives: A comparison between those providing continuity of midwifery care and those not providing continuity. Women Birth. 2018;31(1):38-43, https://doi.org/10.1016/j.wombi. 2017.06.013.

19. Henriksen L, Lukasse M. Burnout among Norwegian midwives and the contribution of personal and work-related factors: A cross-sectional study. Sex Reprod Healthc. 2016;9:42-7, https://doi.org/10.1016/j.srhc.2016.08.001.

20. Newton MS, McLachlan HL, Willis KF, Forster DA. Comparing satisfaction and burnout between caseload and standard care midwives: findings from two cross-sectional surveys conducted in Victoria, Australia. BMC Pregnancy Childbirth. 2014;14:426, https://doi.org/10.1186/s12884014-0426-7.

21. Hildingsson I, Westlund K, Wiklund I. Burnout in Swedish midwives. Sex Reprod Healthc. 2013;4(3):87-91, https:// doi.org/10.1016/j.srhc.2013.07.001.

22. Jordan K, Fenwick J, Slavin V, Sidebotham M, Gamble J. Level of burnout in a small population of Australian mid- wives. Women Birth. 2013;26(2):125-32, https://doi.org/ 10.1016/j.wombi.2013.01.002.

23. Creedy DK, Gamble J. A third of midwives who have experienced traumatic perinatal events have symptoms of post-traumatic stress disorder. Evid Based Nurs. 2016; 19(2):44, https://doi.org/10.1136/eb-2015-102095.

24. Geuens N, Leemans A, Bogaerts A, Van Bogaert P, Franck E. Interpersonal behaviour in relation to burnout. Nurs Manag (Harrow). 2015;22(8):26:28-32, https://doi. org/10.7748/nm.22.8.26.s27.

25. Yoshida Y, Sandall J. Occupational burnout and work factors in community and hospital midwives: a survey analysis. Midwifery. 2013;29(8):921-6, https://doi.org/10.1016/ j.midw.2012.11.002.

26. Mollart L, Skinner VM, Newing C, Foureur M. Factors that may influence midwives work-related stress and burnout. Women Birth. 2013;26(1):26-32, https://doi.org/10.1016/ j.wombi.2011.08.002.

27. Kalicińska M, Chylińska J, Wilczek-Różyczka E. Professional burnout and social support in the workplace among hospice nurses and midwives in Poland. Int J Nurs Pract. 2012;18(6):595-603, https://doi.org/10.1111/ijn.12003.

28. Muliira RS, Ssendikadiwa VB. Professional Quality of Life and Associated Factors Among Ugandan Midwives Working in Mubende and Mityana Rural Districts. Matern Child Health J. 2016;20(3):567-76, https://doi.org/10.1007/s109 95-015-1855-2.

29. Mizuno M, Kinefuchi E, Kimura R, Tsuda A. Professional quality of life of Japanese nurses/midwives providing abortion/childbirth care. Nurs Ethics. 2013;20(5):539-50, https://doi.org/10.1177/0969733012463723.

30. Rees C, Wirihana L, Eley R, Ossieran-Moisson R, Hegney D. The Effects of Occupational Violence on the Well-being and Resilience of Nurses. J Nurs Adm. 2018;48(9): 452-8, https://doi.org/10.1097/NNA.0000000000000648.

31. Ben-Ezra M, Palgi Y, Walker R, Many A, Hamam-Raz Y. The impact of perinatal death on obstetrics nurses: a longitudinal and cross-sectional examination. J Perinat Med. 2014;42(1):75-81, https://doi.org/10.1515/jpm-2013-0071.

32. Warwick C. Midwives can no longer keep services afloat. Nurs Stand. 2016;31(12):27.

33. Hildingsson I, Fenwick J. Swedish midwives' perception of their practice environment - A cross sectional study. Sex Reprod Healthc. 2015;6(3):174-81, https://doi.org/10. 1016/j.srhc.2015.02.001.

34. Pallister C. Surviving shift work. Midwives. 2016;19:70-1.

35. Reiger K, Lane K. "How can we go on caring when nobody here cares about us?" Australian public maternity units as contested care sites. Women Birth. 2013;26(2):133-7, https://doi.org/10.1016/j.wombi.2012.11.003. 
36. Rodwell J, Demir D. Oppression and exposure as differentiating predictors of types of workplace violence for nurses. J Clin Nurs. 2012;21(15-16):2296-305, https://doi.org/ 10.1111/j.1365-2702.2012.04192.x.

37. Farrell GA, Shafiei T, Chan SP. Patient and visitor assault on nurses and midwives: an exploratory study of employer 'protective' factors. Int J Ment Health Nurs. 2014;23(1): 88-96, https://doi.org/10.1111/inm.12002.

38. Birth Project Group. FEAR among midwives. Midwives. 2015;18:60-2.

39. Knezevic B, Milosevic M, Golubic R, Belosevic L, Russo A, Mustajbegovic J. Work-related stress and work ability among Croatian university hospital midwives. Midwifery 2011;27(2):146-53, https://doi.org/10.1016/j.midw. 2009.04.002.

40. Adgie G, Leversidge A. Caring for you. Midwives. 2016; 19:50-2.

41. Midwives disillusioned and burned out finds RCM survey. Pract Midwife. 2013;16(11):8.

42. Askarian M, Shaghaghian S, Gillen M, Assadian O. Body fluid exposure in nurses of Fars province, Southern Iran. Arch Iran Med. 2008;11(5):515-21.

43. Thiede M, Liebers F, Seidler A, Gravemeyer S, Latza U. Gender specific analysis of occupational diseases of the low back caused by carrying, lifting or extreme trunk flexion use of a prevention index to identify occupations with high prevention needs. Am J Ind Med. 2014;57(2):233-44, https://doi.org/10.1002/ajim.22277.

44. Burdelak W, Bukowska A, Krysicka J, Pepłońska B. Night work and health status of nurses and midwives. cross-sectional study. Med Pr. 2012;63(5):517-29.

45. Erdur B, Ergin A, Turkcuer I, Parlak I, Ergin N, Boz B. A study of depression and anxiety among doctors working in Denizli, Turkey.Emerg Med J. 2006;23(10):759-63.

46. Pougnet R, Di Costanzo LP, Kerrien M, Jousset D, Loddé B, Dewitte JD, et al. Occupational factors for mood and anxiety disorders among junior medical doctors. Med Lav. 2015;106(5):386-93.
47. Gao YQ, Pan BC, Sun W, Wang H, Wang JN, Wang L. Anxiety symptoms among Chinese nurses and the associated factors: a cross sectional study. BMC Psychiatry. 2012;12:141, https://doi.org/10.1186/1471-244X-12-141.

48. Sun W, Fu J, Chang Y, Wang L. Epidemiological study on risk factors for anxiety disorder among Chinese doctors. J Occup Health. 2012;54(1):1-8.

49. Cheung T, Yip PS. Depression, Anxiety and Symptoms of Stress among Hong Kong Nurses: A Cross-sectional Study. Int J Environ Res Public Health. 2015;12(9):11072-100, https://doi.org/10.3390/ijerph120911072.

50. Da Silva AT, Lopes CS, Susser E, Menezes PR. Work-Related Depression in Primary Care Teams in Brazil. Am J Public Health. 2016;106(11):1990-7.

51. Waage S, Pallesen S, Moen BE, Magerøy N, Flo E, Di Milia $\mathrm{L}$, et al. Predictors of shift work disorder among nurses: a longitudinal study. Sleep Med. 2014;15(12):1449-55, https://doi.org/10.1016/j.sleep.2014.07.014.

52. Da Silva AT, Peres MF, Lopes C de S, Schraiber LB, Susser E, Menezes PR. Violence at work and depressive symptoms in primary health care teams: a cross-sectional study in Brazil. Soc Psychiatry Psychiatr Epidemiol. 2015 Sep;50(9): 1347-55, https://doi.org/10.1007/s00127-015-1039-9.

53. Mushtaq M, Sultana S, Imtiaz I. The Trauma of Sexual Harassment and its Mental Health Consequences Among Nurses. J Coll Physicians Surg Pak. 2015;25(9):675-9, https://doi.org/09.2015/JCPSP.675679.

54. Karasek R, Brisson C, Kawakami N, Houtman I, Bongers P, Amick B. The Job Content Questionnaire (JCQ): an instrument for internationally comparative assessments of psychosocial job characteristics. J Occup Health Psychol. 1998;3(4):322-55

55. Siegrist J, Siegrist K, Weber I: Sociological concepts in the etiology of chronic disease: the case of ischemic heart disease. Soc Sci Med. 1986;22(2):247-53.

56. Hunter L, Snow S, Warriner S. Being there and reconnecting: Midwives' perceptions of the impact of Mindfulness training on their practice. J Clin Nurs. 2018;27(5-6) 1227-38, https://doi.org/10.1111/jocn.14169.

This work is available in Open Access model and licensed under a Creative Commons Attribution-NonCommercial 3.0 Poland License - http://creativecommons.org/licenses/by-nc/3.0/pl/deed.en. 